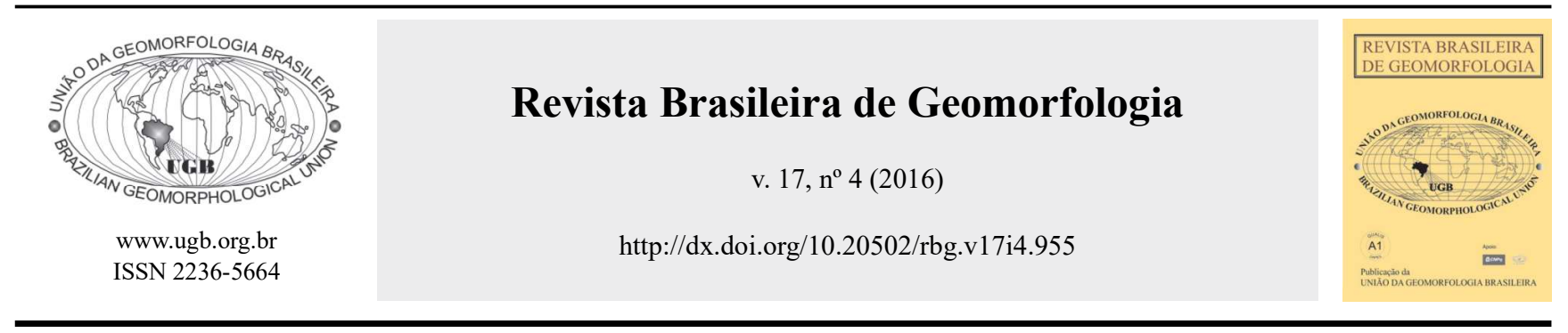

\title{
MORFODINÂMICA DO PONTAL ARENOSO E INTERFERÊNCIAS NA EVOLUÇÃO DA PLANÍCIE DE MARÉ NA DESEMBOCADURA DO RIO SERGIPE - ARACAJU/SE
}

\section{MORPHODYNAMICS OF THE SANDY SPIT AND INTERFERENCES IN THE EVOLUTION OF THE TIDAL FLAT AT THE MOUTH OF SERGIPE RIVER - ARACAJU/SE}

\author{
Geisedrielly Castro dos Santos \\ Departamento de Geografia, Universidade Federal de Sergipe \\ Av. Marechal Rondon, s/n Jardim Rosa Elze, São Cristóvão, Sergipe. CEP 49100-000. Brasil \\ Email: geisecastrosantos@hotmail.com \\ Rosemeri Melo e Souza \\ Departamento de Geografia, Universidade Federal de Sergipe \\ Av. Marechal Rondon, s/n Jardim Rosa Elze, São Cristóvão, Sergipe. CEP 49100-000. Brasil \\ Email:romeufs@ufs.br
}

Informações sobre o Artigo

Recebido (Received):

29/12/2015

Aceito (Accepted):

06/09/2016

\section{Palavras-chave:}

Dinâmica fluviomarinha; Erosão; Mangue.

\section{Keywords:}

Fluviomarine dynamics; Erosion; Mangrove.

\section{Resumo:}

As desembocaduras fluviais possuem dinâmica complexa quando estas se encontram em ambientes costeiros. Os estudos desses sistemas ambientais na Geografia Física podem ser alicerçados pela Geoecologia das paisagens, a partir da análise da estrutura, função, dinâmica e evolução das paisagens. A área de estudo corresponde a planície de maré entre os bairros 13 de Julho e Jardins e o pontal arenoso situado no bairro Coroa do Meio, localizados na desembocadura do rio Sergipe no município de Aracaju-SE. Devido à morte da vegetação de mangue e ao aumento da sedimentação sobre a planície de maré (entre os anos de 2013 e 2014) surgiu à necessidade de se analisar as causas desses processos. $\mathrm{O}$ objetivo do presente trabalho foi analisar as alterações morfodinâmicas do promontório arenoso da Coroa do Meio e suas interferências sobre a planície de maré entre os bairros 13 de Julho e Jardins no período entre 2004 e 2014. Para este trabalho foram elencados os seguintes procedimentos metodológicos: Trabalho de campo; Processamento das imagens de satélite, Mapeamentos temáticos; Quantificação das classes temáticas e Interpretação dos dados. Os resultados mostraram que a redução na área da planície de maré e morte do mangue foi promovida pela sedimentação oriunda da erosão da extremidade do pontal arenoso da Coroa do Meio, fato que também promoveu o avanço das ondas sobre parte da infraestrutura urbana do município. Concluiu-se com a realização 
deste trabalho que a dinâmica do sistema ambiental em questão é regulada pela migração do talvegue do rio Sergipe em direção ao sul e pela ação dos agentes oceanográficos. Esta pesquisa fornece subsídios para análises futuras que visem o planejamento ambiental em áreas costeiras urbanizadas.

\begin{abstract}
:
River mouths have complex dynamics when they are in coastal environments. Studies on these environmental systems in Physical Geography can be based on Landscape Geoecology, from the analysis of the structure, function, dynamics and evolution of landscapes. The study area refers to a tidal flat between 13 de Julho and Jardins neighborhoods and the sandy spit located in Coroa do Meio neighborhood, at the mouth of Sergipe River in the city of Aracaju/Sergipe state. Due to the death of mangrove vegetation and the increase of sedimentation on the tidal flat (between 2013 and 2014), it became necessary to investigate the causes of these processes. The aim of this study is to analyze the morphodynamics changes of the sandy promontory in Coroa do Meio and their influences on the tidal flat between 13 de Julho and Jardins neighborhoods from 2004 to 2014. For this work, the following methodological procedures were accomplished: fieldwork; satellite image processing, thematic mappings; quantification of thematic classes and data interpretation. The results showed that the reduction in the tidal flat area and the death of the mangrove were promoted by a sedimentation which was caused by the erosion of the extremity of the sandy spit in Coroa do Meio, a fact that also promoted the progress of waves over parts of the urban infrastructure of the city. It has been concluded, throughout this work, that the dynamics of the environmental system in question is regulated by the migration of the thalweg of Sergipe River towards the south and the action of oceanographic agents. This research study provides a basis for future analysis aimed at environmental planning in urban coastal areas.
\end{abstract}

\section{Introdução}

A configuração atual das planícies costeiras na costa leste do Brasil originou-se a partir das flutuações do nível relativo do mar durante o Quaternário (SUGUIO \& MARTIN, 1978). Mais especificamente para os estados de Sergipe e Alagoas, um modelo esquemático foi produzido por Bittencourt et al. (1983) para refletir esse processo de formação a partir das transgressões e regressões marinhas. Os principais eventos associados à evolução paleogeográfica quaternária foram responsáveis pelo retrabalhamento da Formação Barreiras, sendo eles: O afogamento dos vales fluviais, Deposição dos sedimentos no sopé das falésias formadas, conjuntamente com materiais de origem orgânica; Deposição de sedimentos de origem eólica e Formação dos terraços marinhos pleistocênicos e holocênicos.

Os seis estuários que cortam a planície costeira sergipana atualmente foram originados durante os episódios relacionados aos eventos de transgressão e regressão citados anteriormente. Contudo, cada região estuarina possui uma dinâmica peculiar, própria dos processos condicionantes que atuam em sua modelagem, sejam de origem oceanográfica (regime de marés, ondas e correntes litorâneas), fluviais (descarga fluvial), atmosféricas (precipitações e dinâmica eólica) e/ou de interferências antrópicas (TESSLER \& CAZZOLI Y GOYA, 2005).

A dinâmica estuarina no estado de Sergipe favoreceu a formação de ambientes de planícies de marés em todas as desembocaduras fluviais. Para que ocorram o desenvolvimento de áreas de planícies de marés e posterior colonização pela vegetação é necessário que existam áreas abrigadas da ação mecânica das ondas e que estas sofram a influência do regime de marés (ZENKOVICH, 1967; ANGULO, 1990). Em Sergipe o ecossistema desenvolvido sobre esses ambientes é o manguezal, caracterizado assim pela vegetação que se desenvolve conhecida como mangue.

O estudo de dinâmica em ambientes estuarinos pode ser alicerçado pela análise geoecológica da paisagem, com a finalidade de se identificar os componentes do sistema (Estrutura); as relações entre os componentes biofísicos e antrópicos, bem como o papel que cada um desempenha (Função) e como ocorrem os fluxos de matéria e energia dentro do sistema ambiental (Dinâmica), 
como aporte para análise de cenários futuros (Evolução) (TROLL, 1970).

No município de Aracaju (capital do estado de Sergipe) as áreas de ecossistemas manguezais sofreram processos intensos de degradação a partir da década de 1970, com o crescimento urbano do município. Dentre as intervenções antrópicas sobre esses ambientes incluem-se: o corte da vegetação de mangue e aterramento das planícies de marés para instalação da infraestrutura urbana e poluição das águas fluviais pelo despejo da rede de esgoto diretamente sobre a desembocadura fluvial (SANTOS, 2012). A situação verificada demonstra a necessidade de estudos geoecológicos em ambientes estuarinos urbanizados tendo em vista a conservação de manguezais e quaisquer ecossistemas associados.

\section{Área de estudo}

A área de estudo do presente trabalho está localizada na desembocadura do rio Sergipe, no município de Aracaju/SE, na área de confluência com seu tributário rio Poxim, desaguando no Oceano Atlântico. Esta corresponde ao pontal arenoso formado no bairro Coroa do Meio e a área de planície de maré entre os bairros 13 de Julho e Jardins (Figura 1), região situada entre as coordenadas: $10^{\circ} 56^{\prime} 30^{\prime \prime} \mathrm{S} ; 10^{\circ} 55^{\prime} 45^{\prime \prime}$ 'S e $37^{\circ} 2^{\prime} 25^{\prime \prime} \mathrm{W}$; 37³'W.

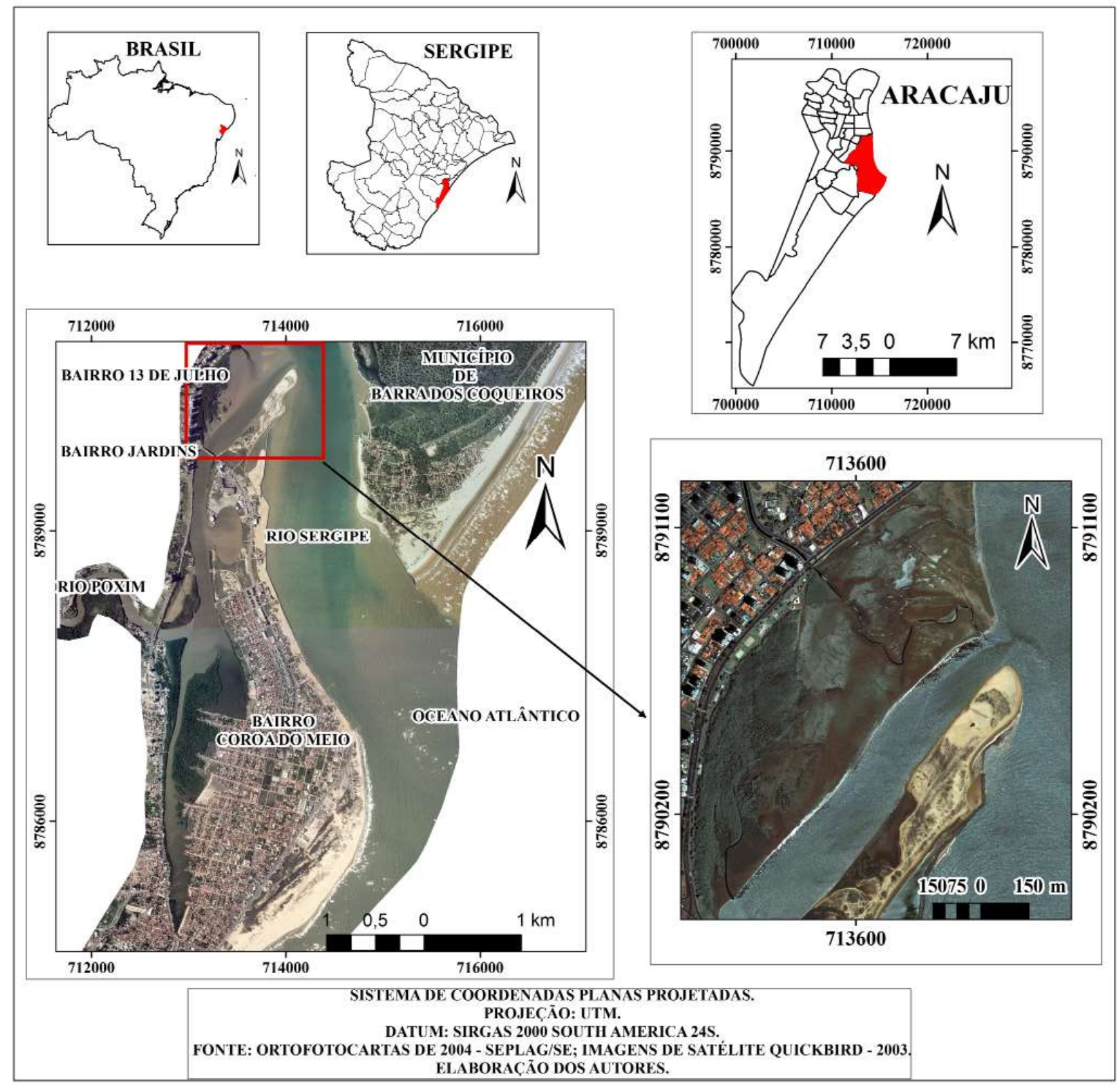

Figura 1 - Localização da área de estudo. Pontal arenoso formado no bairro Coroa do Meio e a área de Planicie de maré entre os bairros 13 de Julho e Jardins - Aracaju/Sergipe/Brasil. 
A dinâmica fluviomarinha na área de estudo é possivelmente mais influenciada pela ação marinha, quando comparado os dados de clima de ondas e vazão média fluvial. A altura das ondas que atingem o município de Aracaju varia entre 1 e $3 \mathrm{~m}$, de acordo com as estações do ano, esse valores forem estimados por Oliveira (2003) e Pianca; Mazzini; Siegle (2010). A análise dos dados de vazões médias anuais do rio Sergipe mostrou uma média de 2,44 m³/s, entre as décadas de 1990 e 2015 (conforme os dados da Agência Nacional de Águas- ANA) podendo ser considerada pouco expressiva. A bacia hidrográfica do rio Sergipe possui como característica uma intensa demanda para utilização dos seus recursos hídricos com forte demanda para o setor agroindustrial e intensa urbanização (SEMARH, 2011), o que justifica a pouca expressividade da descarga fluvial tendo em vista que a pluviosidade média anual varia em torno de 1500 a $1600 \mathrm{~mm}$ (SRH, 2011).
A configuração atual da desembocadura teve seu processo de formação associado ao crescimento de duas coroas arenosas (Figura 2). Essas coroas arenosas possuíam inúmeros canais de maré, sendo divididas por três canais principais (Norte, Central e Sul), por onde o rio Sergipe e o rio Poxim entravam em contato com o Oceano Atlântico. Devido à dinâmica fluviomarinha no local, emergiram de forma gradativa nas coroas alguns pontais arenosos, sendo estes os responsáveis pela consolidação das duas coroas e posterior ligação ao município de Aracaju pela restinga existente no bairro Atalaia (chamado à época de pontal sul). A consolidação das coroas arenosas permitiu o alargamento do canal Norte, fechando o canal Central e isolando o canal $\mathrm{Sul}$ (atual foz do rio Poxim). O isolamento do canal Sul permitiu o desenvolvimento de uma extensa área de planície de maré no local, e posteriormente ocorreu a colonização pelo mangue (WANDERLEY, 2006; SANTOS, 2012; SANTOS, 2014).

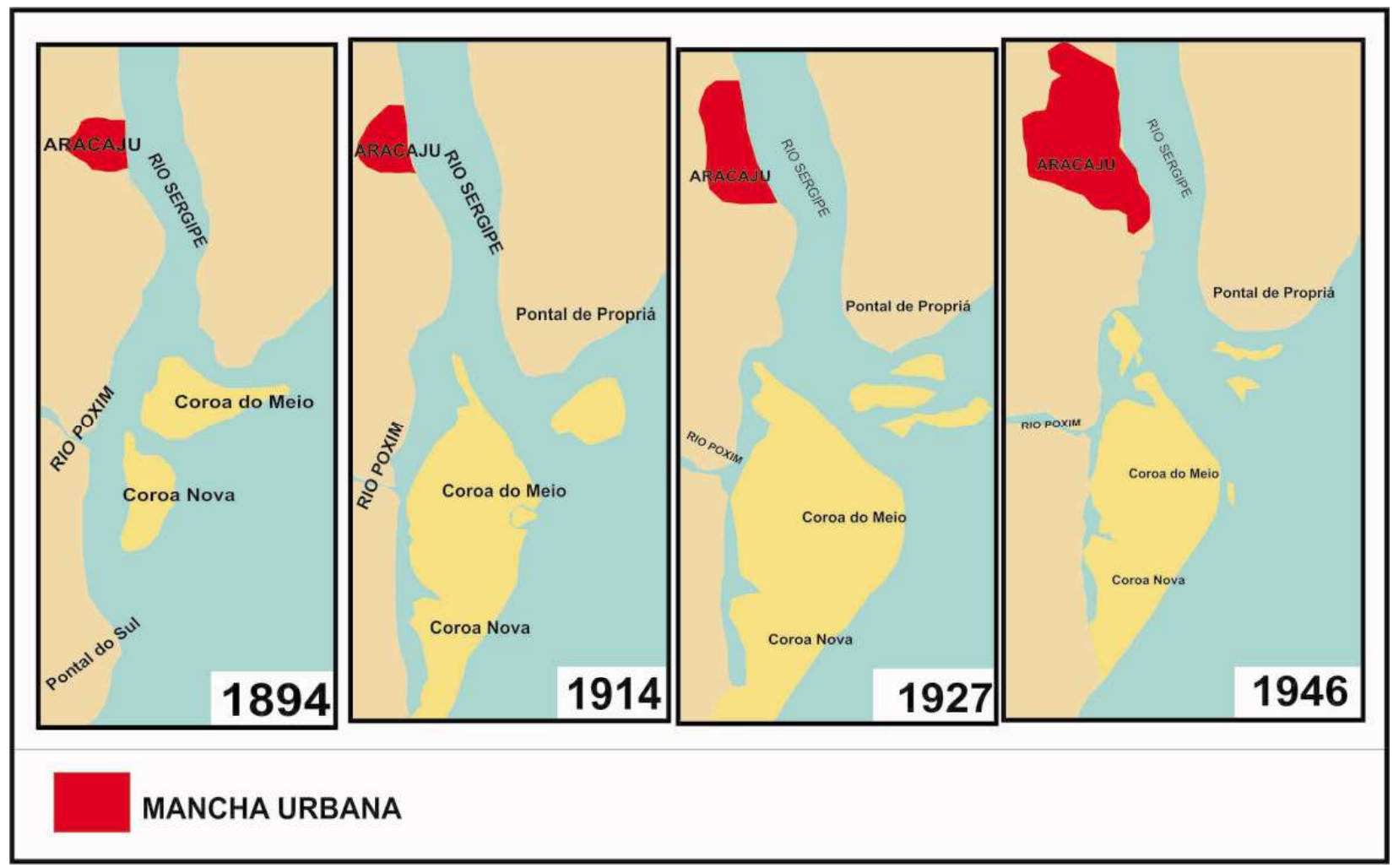

Figura 2 - Evolução da desembocadura do Rio Sergipe e formação da área de estudo. Fonte: Modificado das cartas náuticas da DHNDiretoria de Hidrografia e Navegação (1894, 1914, 1927 e 1946).

O surgimento da área de estudo do presente artigo foi explicado por Santos (2014). Através da análise multitemporal de fotografias aéreas e imagens de satélites, a autora verificou que o promontório arenoso da Coroa do Meio teve seu processo de formação iniciado entre
1955 e 1965, já com as coroas arenosas consolidadas. No entanto, ainda não possuía dimensão suficiente para proteger a área de planície de maré entre os bairros 13 de Julho e Jardins, sendo esta exposta constantemente à ação direta das ondas oceânicas. Entre 1978 e 2003 
ocorreu o processo de urbanização de todo bairro Coroa do Meio incluindo a instalação de uma obra de engenharia costeira (molhe) com a finalidade de proteger o local dos episódios erosivos. O molhe foi construído a partir da área onde se localizava o pontal arenoso, essa construção promoveu o seu crescimento, pois permitiu maior acúmulo de sedimentos. O crescimento do pontal arenoso foi determinante para o desenvolvimento da planície de maré entre os bairros 13 de Julho e Jardins e posterior colonização pelo mangue.

A expansão da urbanização sobre o município de Aracaju promoveu a canalização dos canais de marés que se comunicam com o manguezal da área de estudo bloqueando o escoamento das águas fluviomarinhas e ocasionando constantes alagamentos sobre os bairros 13 de Julho e Jardins. A dinâmica fluviomarinha também promoveu o avanço das ondas sobre parte da Avenida Beira Mar que margeia a desembocadura do rio Sergipe e de seu afluente o rio Poxim. Aliado a esses episódios, entre os anos de 2012 e 2013, foram observadas ao longo do bairro 13 de Julho a morte da vegetação do manguezal, sendo que esse fenômeno foi investigado pela Administração Estadual do Meio Ambiente - ADEMA que apontou como principal causa a sedimentação na área de planície de maré (SANTANA, 2012). A partir do exposto surgiu a necessidade de se verificar a correlação entre os processos morfodinâmicos na desembocadura do rio Sergipe e a dinâmica da planície de maré, na tentativa de elucidar a origem dessa sedimentação. Para tal foi elaborado o presente artigo com o objetivo de analisar as alterações morfodinâmicas do promontório arenoso da Coroa do Meio e suas interferências sobre a planície de Maré entre os bairros 13 de Julho e Jardins no período entre 2004 e 2014.

\section{Materiais e Métodos}

Norteado pelo método da Geoecologia das paisagens (TROLL, 1970), que possui como princípio fundamental a análise da: Estrutura, Função e Dinâmica das paisagens, foram elencados os seguintes procedimentos metodológicos: Trabalho de campo; Aquisição, processamento das imagens de satélite, criação dos shapes e construção dos mapeamentos temáticos; quantificação da área de cada uma das classes temáticas e interpretação dos dados.

\section{Trabalho de campo:}

Tendo em vista as alterações visualizadas nos manguezais entre os anos de 2012 e 2013 houve a necessidade de realização de visitas in loco para averiguar a situação atual da área de estudo.

O trabalho de campo foi realizado levando-se em consideração o regime de marés, com opção pelas marés de sizígia (marés mais baixas e marés mais altas) que ocorrem durante as fases de Lua cheia e Lua nova (NETO et al., 2004). Os dias escolhidos foram: o dia 24 de Janeiro de 2015 durante a maré baixa, da lua cheia, no período da tarde (altura da maré 0.3 a partir das 12 : $32 \mathrm{~h}$ ) e 25 de Janeiro de 2015 durante a maré alta, da lua nova, no período da tarde (altura da maré 2.2 a partir das 16:13h).

A visita realizada durante a maré baixa foi necessária para observação e registro fotográfico da planície de maré desprovida de mangue e colonizada pelo mesmo com maior área exposta. E a visita durante a maré alta proporcionou a visualização da exposição do manguezal à intrusão das águas estuarinas.

\section{Aquisição e processamento das imagens de satélite e fotografias aéreas:}

A análise multitemporal para esta pesquisa consistiu no melhor instrumento para verificar o funcionamento e a dinâmica da área de estudo. Para sua execução foram utilizadas imagens do satélite Quickbird de alta resolução, adquiridas e cedidas pela Empresa Municipal de Obras e Urbanização - EMURB/SE, e Fotografias aéreas, cedidas pela Secretaria de Planejamento Orçamento e Gestão - SEPLAG/SE. As imagens e fotografias aéreas utilizadas bem como suas informações estão descritas na Tabela 1.

O processamento das imagens de satélite e das fotografias aéreas foi dividido em duas etapas: retificação do datum horizontal e do georeferenciamento.

No SIG ArcGis v.12.2.1 foram feitas as importações das imagens de satélite dos anos de 2008, 2011 e 2014 e das fotografias aéreas do ano de 2004. Posteriormente foi feita a correção do datum horizontal de SAD 1969 para SIRGAS 2000.

Após a retificação do datum foi feita a retificação do georeferenciamento das imagens de satélite utili- 
Tabela 1: Informações sobre as imagens de satélite e fotografias aéreas utilizadas na pesquisa.

\begin{tabular}{c|c|c}
\hline ANO & TIPO DE IMAGEM & ESCALA/RESOLUÇÃO \\
\hline 2004 & Fotografias aéreas & $1: 10.000$ \\
2008 & Imagens do satélite Quickbird & $2,62 \mathrm{~m}$ (multiespectral) \\
2011 & Imagens do satélite Quickbird & $2,62 \mathrm{~m}$ (multiespectral) \\
2014 & Imagens do satélite Quickbird & $2,40 \mathrm{~m}$ (multiespectral) \\
\hline
\end{tabular}

zando como referência as fotografias aéreas do ano de 2004, executadas pela SEPLAG/SE e que compõem a base cartográfica do estado de Sergipe. O georeferenciamento foi efetuado com auxílio do SIG Quantum Gis v.2.0.1. Essa etapa permitiu que as imagens de satélite e as fotografias aéreas pudessem ser sobrepostas quando necessário, a fim de facilitar a análise evolutiva.

\section{Vetorização, criação dos arquivos em shapefile e confeç̧ão} dos mapas temáticos.

No SIG ArcGis v.12.2.1 foi efetuada a criação das classes temáticas no formato shapefile (.shp). As principais classes temáticas vetorizadas foram: Planície de maré desprovida de mangue; Mangue; Pontal arenoso emerso e submerso e Banco arenoso. Todas as vetorizações foram efetuadas com escala fixa de mapeamento de 1 : 2000 , suficiente para a visualização de todos os atributos presentes nas imagens de satélite e fotografias aéreas.

Após a vetorização das classes temáticas e posterior criação dos polígonos foi realizada a medição da área das classes temáticas: Planície de maré desprovida de mangue; Mangue; Pontal arenoso emerso e submerso e Banco arenoso. A medição foi efetuada observando os valores de área de cada polígono, presentes na tabela de atributos de cada classe, com exceção da classe Pontal arenoso emerso, que foi medida com auxílio da ferramenta measure, esta opção foi tomada devido à necessidade de somente medir a área que sofreu erosão e que possui relevância para a pesquisa.

Os mapas temáticos tiveram como objetivo representar os principais elementos da área de estudo. Foram realizados para esta pesquisa mapeamentos relativos aos anos de 2004, 2008, 2011 e 2014.

\section{Quantificação da área das classes temáticas.}

Para quantificar a área de cada uma das classes temáticas relevantes para o trabalho foram adotadas duas formas de quantificação: a primeira foi extrair os dados da tabela de atributos de cada shape criado, sendo o resultado mensurado em quilômetros quadrados $\left(\mathrm{km}^{2}\right)$; a segunda foi utilizar a ferramenta measure na opção measure an area. Este procedimento foi adotado para quantificar a área erodida da classe Pontal arenoso (localizada após o molhe construído) utilizando como referência a última imagem quickbird e/ou fotografia aéreo analisado.

\section{Resultados}

Morfodinâmica do pontal arenoso e interferências na evolução da planície de maré - 2004 e 2008.

A análise efetuada para os anos de 2004 e 2008 revelou que o pontal arenoso existente no bairro Coroa do Meio sofreu erosão na região localizada após o molhe, fato que pode ser comprovado a partir da quantificação na Tabela 2 , onde os valores de área se alteram entre 2004 e 2008 de $0,063 \mathrm{~km}^{2}$ para $0,043 \mathrm{~km}^{2}$, respectivamente, e da observação da Figura 3. Mesmo com a erosão sofrida no promontório arenoso verificou-se aumento na área colonizada pelo mangue, de $0,168 \mathrm{~km}^{2}$ para $0,223 \mathrm{~km}^{2}$ entre 2004 e 2008, respectivamente. Nessa circunstância o pontal arenoso cumpre a função de resguardar a planície de maré da ação mecânica das ondas. Contudo, foi observada pequena redução na área de planície de maré desprovida de mangue passando de $0,45 \mathrm{~km}^{2} \mathrm{em} 2004$ para $0,36 \mathrm{~km}^{2} \mathrm{em} 2008$. Realizando-se um somatório entre as áreas desprovidas e colonizadas por mangue para cada ano, verificou-se que a redução de fato na unidade geoecológica planície de maré foi de $0,035 \mathrm{~km}^{2}$, entre 2004 e 2008 (Tabela 3).

Na Figura 3 ainda é possível verificar o desenvolvimento de uma área de planície de maré no pontal arenoso, na retaguarda do molhe e na parte interna do antigo canal sul do rio Sergipe. Com valores de área de $0,032 \mathrm{~km}^{2} \mathrm{em}$ 2004 e $0,080 \mathrm{~km}^{2} \mathrm{em} 2008$. Corroborando com as observações de que mesmo sofrendo erosão o pontal arenoso ainda fornece proteção para as áreas de planícies de maré. 
Tabela 2: Área em quilômetros quadrados das classes temáticas.

\begin{tabular}{|c|c|c|c|c|c|c|}
\hline ANO & $\begin{array}{c}\text { Planície } \\
\text { de maré } \\
\text { desprovida } \\
\text { de mangue } \\
\left(\mathrm{km}^{2}\right)\end{array}$ & $\begin{array}{c}\text { Vegetação } \\
\text { de } \\
\text { mangue } \\
\left(\mathbf{k m}^{2}\right)\end{array}$ & $\begin{array}{c}\text { Área do } \\
\text { pontal } \\
\text { arenoso } \\
\left(\mathbf{k m}^{2}\right)\end{array}$ & $\begin{array}{c}\text { Pontal } \\
\text { submerso } \\
\text { visível } \\
\left(\mathbf{k m}^{2}\right)\end{array}$ & $\begin{array}{c}\text { Planície de } \\
\text { maré (com e } \\
\text { sem mangue) no } \\
\text { pontal arenoso } \\
\left(\mathbf{k m}^{2}\right)\end{array}$ & $\begin{array}{l}\text { Banco arenoso na } \\
\text { Planície de maré } \\
\text { da } 13 \text { de Julho e } \\
\text { Jardins }\left(\mathbf{k m}^{2}\right)\end{array}$ \\
\hline 2004 & 0,447 & 0,168 & 0,063 & - & 0,032 & - \\
\hline 2008 & 0,357 & 0,223 & 0,043 & - & 0,080 & - \\
\hline 2011 & 0,325 & 0,264 & 0,006 & 0,05 & 0,097 & - \\
\hline 2014 & 0,275 & 0,256 & - & 0,03 & 0,097 & 0,006 \\
\hline
\end{tabular}

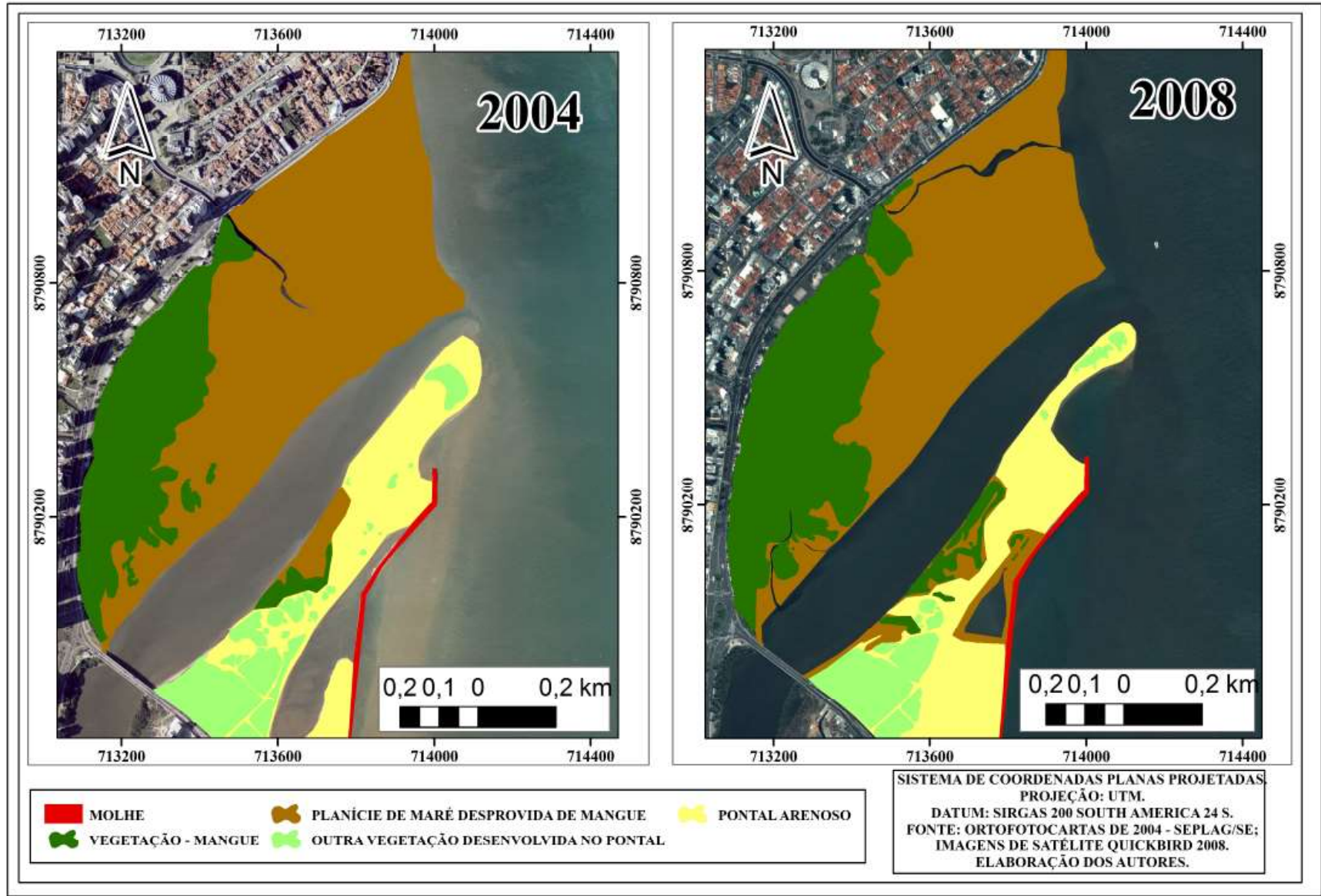

Figura 3-Evolução da região do pontal arenoso e da planície de maré entre os bairros: Coroa do Meio, 13 de Julho e Jardins - 2004 e 2008.

Tabela 3: Comparativo da área das unidades: Planície de maré desprovida e colonizada pelo mangue.

\begin{tabular}{c|c|c}
\hline ANO & $\begin{array}{c}\text { Planície de maré desprovida de } \\
\text { mangue }\left(\mathbf{k m}^{\mathbf{2}}\right)\end{array}$ & Vegetação de mangue $\left(\mathbf{k m}^{\mathbf{2}}\right)$ \\
\hline $2004-2008$ & $-0,035$ & $+0,055$ \\
$2008-2011$ & $-0,032$ & $+0,041$ \\
$2011-2014$ & $-0,050$ & $-0,008$ \\
\hline
\end{tabular}


Morfodinâmica do pontal arenoso e interferências na evolução da planície de maré - 2008 e 2011.

Acompanhando a tendência verificada na análise entre 2004 e 2008, no período entre 2008 e 2011 ocorreu discreta redução na área da planície de maré desprovida de mangue e aumento na área colonizada pelo mangue
(Tabela 2 e Figura 4). Fazendo-se um comparativo entre a redução dos valores de área da planície desprovida de mangue com a área acrescida de vegetação, entre 2008 e 2011, concluiu-se que a redução verificada na área desprovida se deu em parte pela colonização do mangue, conforme é possível visualizar na tabela 3 .

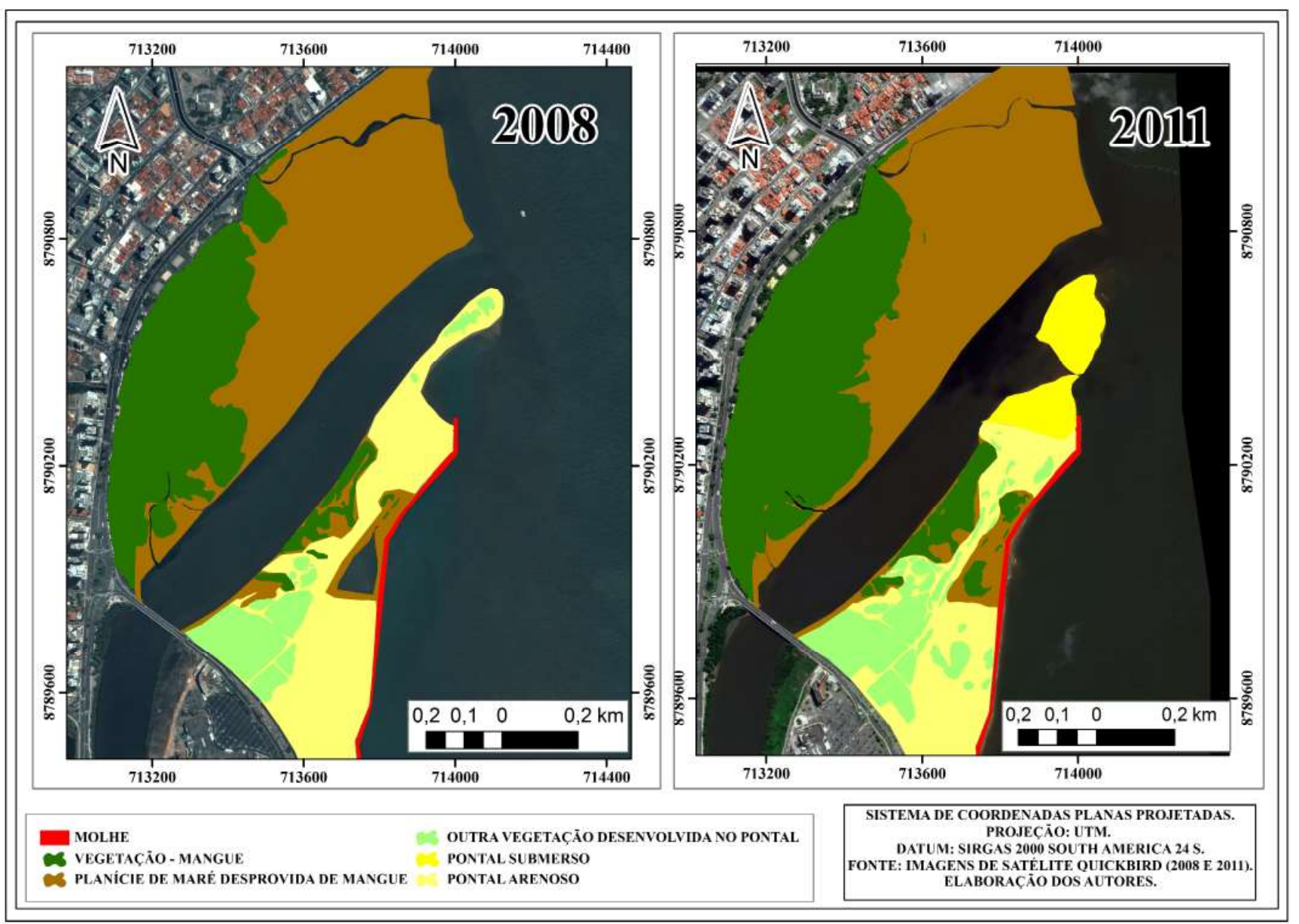

Figura 4 - Evolução da região do pontal arenoso e da planicie de maré entre os bairros: Coroa do Meio, 13 de Julho e Jardins - 2008 e 2011.

No que concerne ao pontal arenoso da Coroa Meio foi verificada nova redução de área na extremidade próxima ao final do molhe em virtude da erosão (Tabelas 2, 3 e Figura 4). Na Figura 4, no ano de 2011, toda a área erodida ainda é visível de forma submersa, graças à alta resolução da imagem Quickbird (na Figura $4 \mathrm{o}$ pontal submerso está representado na cor verde musgo). A área na extremidade do pontal arenoso emerso (próximo ao molhe), entre 2008 e 2011, passou de 0,043 $\mathrm{km}^{2}$ para $0,006 \mathrm{~km}^{2}$, respectivamente. A área submersa em 2011 possuía valor de área de $0,050 \mathrm{~km}^{2}$, o que indica que grande parte do material erodido ainda não havia migrado em direção ao canal do rio Sergipe ou em direção ao oceano, de acordo com a predominância dos agentes fluviomarinhos. Verificou-se também que o manguezal existente no pontal arenoso se expandiu de $0,080 \mathrm{~km}^{2}$ em 2008 para $0,097 \mathrm{~km}^{2} \mathrm{em} 2011$, resultado da área estável consolidada e protegida da ação das ondas. O comparativo da dinâmica existente no período entre 2008 e 2011 mostrou que ocorreu pouca alteração na área total do manguezal entre os bairros 13 de Julho e Jardins, o que indica que o pontal arenoso mesmo sofrendo erosão continua a cumprir com sua função de resguardar o manguezal da ação mecânica das ondas. 
Morfodinâmica do pontal arenoso e interferências na evolução da planície de maré - 2011 e 2014.

Dentre todas as análises multitemporais apresentadas até o momento foi verificado que o pontal arenoso, apesar de ter sofrido redução devido aos processos erosivos, protegia a planície de maré (com e sem mangue) da ação direta das ondas, promovendo a sua estabilização e expansão (Tabelas 2 e 3). Contudo, a análise do período entre 2011 e 2014 revela uma nova dinâmica na área de estudo (Figura 5).
Entre 2011 e 2014, a área correspondente a planície desprovida de mangue reduziu de $0,325 \mathrm{~km}^{2}$ para $0,275 \mathrm{~km}^{2}$, respectivamente, assim como a área colonizada por mangue que passou de $0,264 \mathrm{~km}^{2} \mathrm{em} 2011$ para $0,256 \mathrm{~km}^{2} \mathrm{em}$ 2014 (Tabela 2). Na tabela 3 é possível perceber que na análise entre 2011 e 2014 houve redução de $0,050 \mathrm{~km}^{2}$ na planície de maré desprovida de mangue e $0,008 \mathrm{~km}^{2}$ na área colonizada pelo mangue. Na situação analisada verifica-se que não houve acréscimo na colonização por mangue diferentemente das análises entre 2004 e 2011. Entre 2011 e 2014 o manguezal começou a ter sua dinâmica alterada.

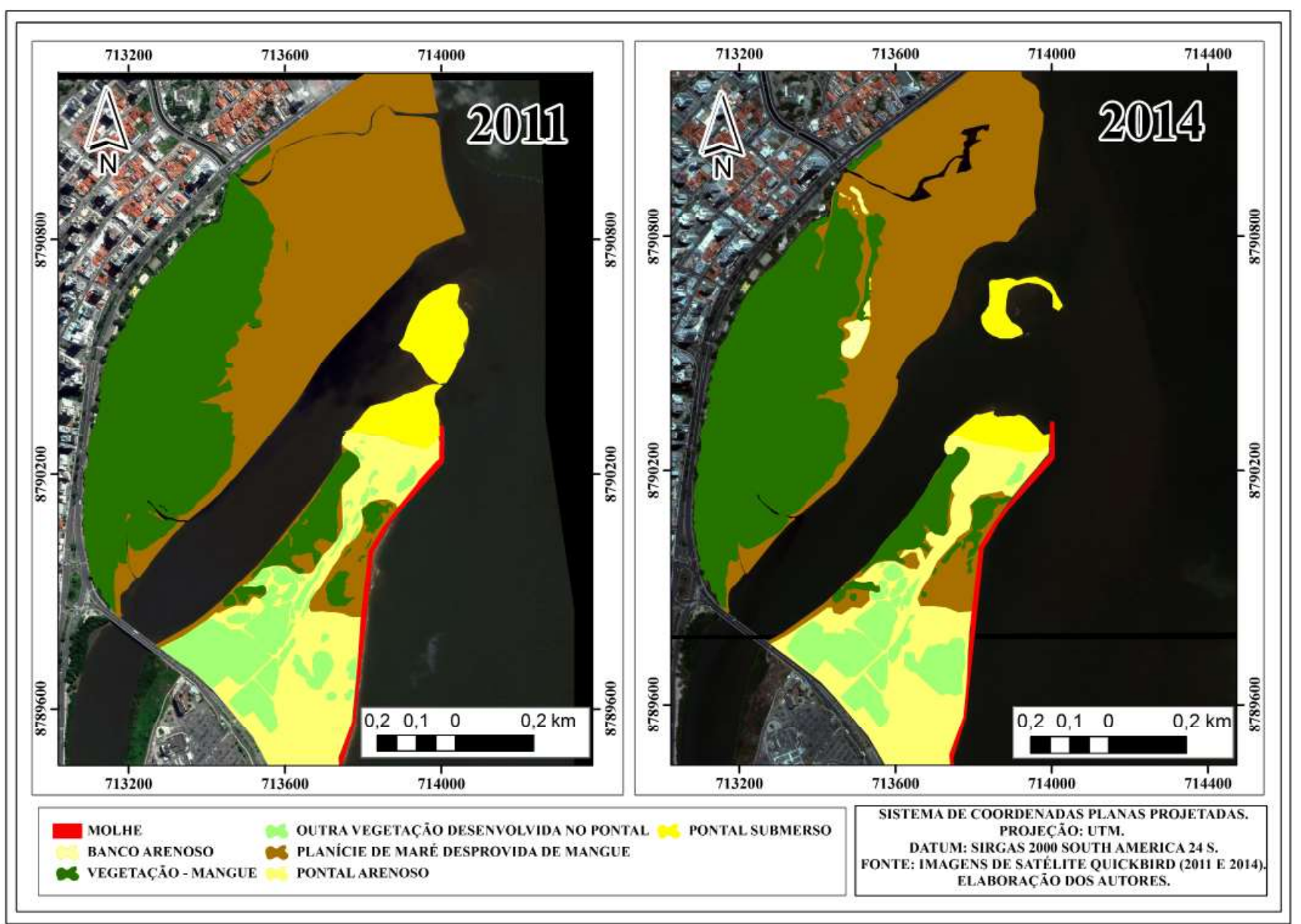

Figura 5 - Evolução da região do pontal arenoso e da planície de maré entre os bairros: Coroa do Meio, 13 de Julho e Jardins - 2011 e 2014.

As principais causas para a redução na área do manguezal entre os bairros 13 de Julho e Jardins se justificam pelas alterações encontradas no pontal arenoso na análise de 2014. A figura 6-A ilustra as alterações sofridas pelo promontório arenoso da Coroa do Meio devido à erosão entre 2004 e 2014 e na figura 6-B a área de sedimentação submersa entre 2011 e 2014. Observando-se a Figura 5, na classe correspondente ao pontal submerso, percebe-se que o mesmo migra em direção ao manguezal também é possível perceber que no ano de 2014 na área colonizada pelo mangue existe um banco arenoso. Os valores de área revelam que em 2011 o pontal submerso possuía área de $0,050 \mathrm{~km}^{2}$ e em $20140,03 \mathrm{~km}^{2}$, parte desse material sedimentar submerso atingiu o manguezal dando origem ao banco arenoso visualizado na Figura 5. É válido ressaltar que a área de pontal arenoso emerso em 2014 (nas proximidades do molhe) já não existe mais. Com uma área de $0,006 \mathrm{~km}^{2}$, o banco arenoso (oriundo da erosão 
do pontal arenoso da Coroa do Meio) localizado no manguezal no ano de 2014 foi responsável pela redução na área colonizada pelo mangue, devido ao assoreamento. Essa constatação corrobora com a análise da Secretaria do Meio Ambiente e dos Recursos Hídricos de Sergipe-
SEMARH, que a partir de estudos identificou como causa para a morte da vegetação de mangue a sedimentação (SANTANA, 2012). Contudo, os estudos da SEMARH não identificaram a origem da sedimentação, fato apresentado pela análise realizada no presente artigo.

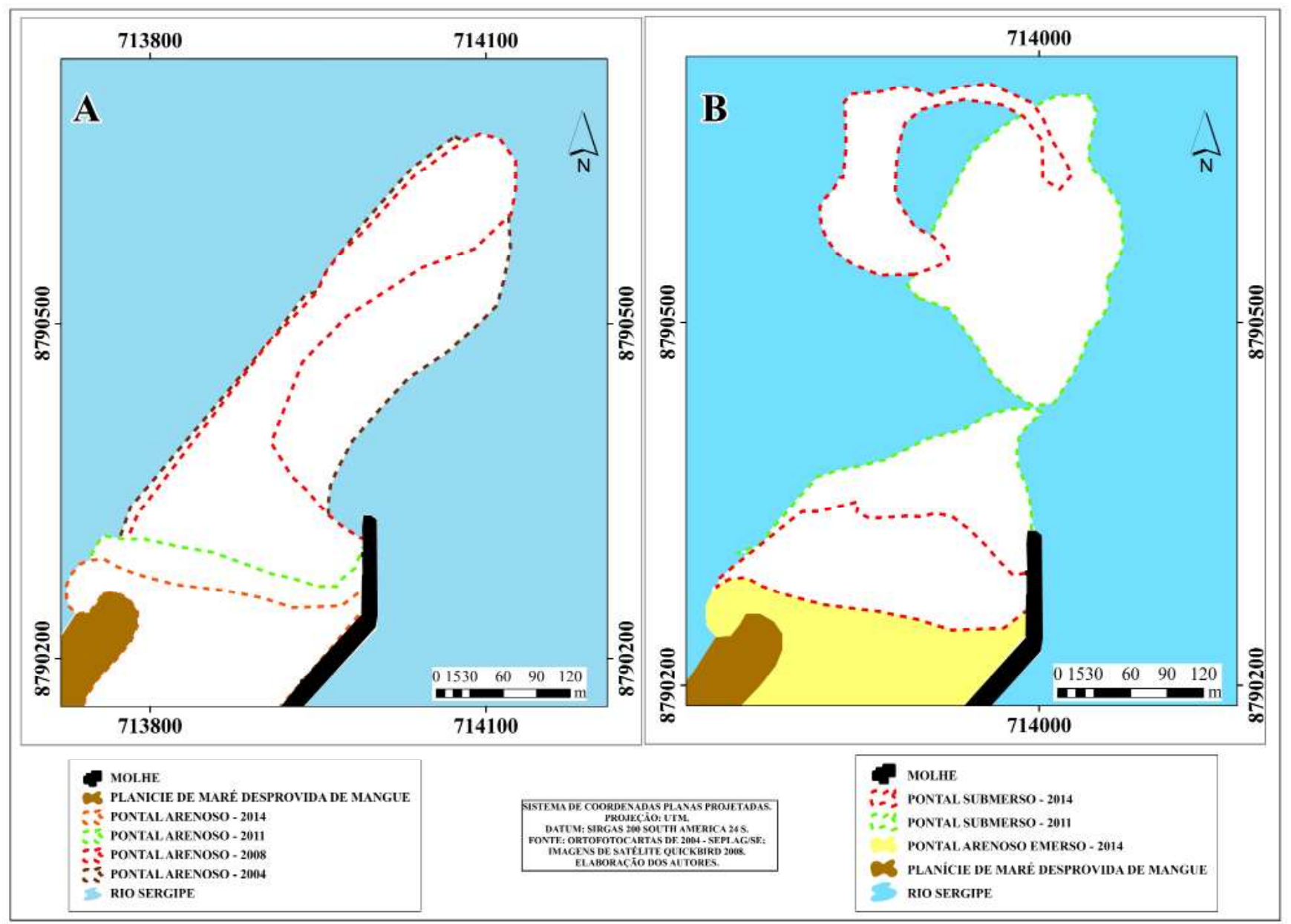

Figura 6 - Erosão do Pontal arenoso no periodo entre 2004 e 2014.

A figura 7 apresenta um mosaico de fotografias realizadas durante o trabalho de campo no ano de 2015. As fotos foram feitas durante a maré baixa com a finalidade de registrar maior exposição da planície de maré. É possível identificar a morte da vegetação no comparativo entre a imagem Quickbird de 2011 e as fotografias de 2015 (Figura 7A, B e C), com o agravante de que em 2015 toda a área de mangue localizada nas proximidades do calçadão do bairro 13 de Julho foi substituída por uma obra de engenharia costeira, destinada a contenção do avanço das ondas sobre a pista asfaltada (Figura 7D), fato este também decorrente da erosão de parte do pontal arenoso da Coroa do Meio. Na figura 8 é possível perceber a obra de contenção durante a maré alta (8A) e a vegetação de mangue morta (8B).

\section{Discussão}

FitzGerald et al. (2000) e FitzGerald (1982) explicam os mecanismos de transportes básicos de sedimentos em desembocaduras fluviais. Dentre os nove modelos apresentados pelos autores, a desembocadura da área de estudo se encaixa no modelo 3: Rompimento do Delta de Maré vazante (entende-se por delta de maré vazante a presença de bancos arenosos existentes nas desembocaduras provenientes das vazantes das marés). 


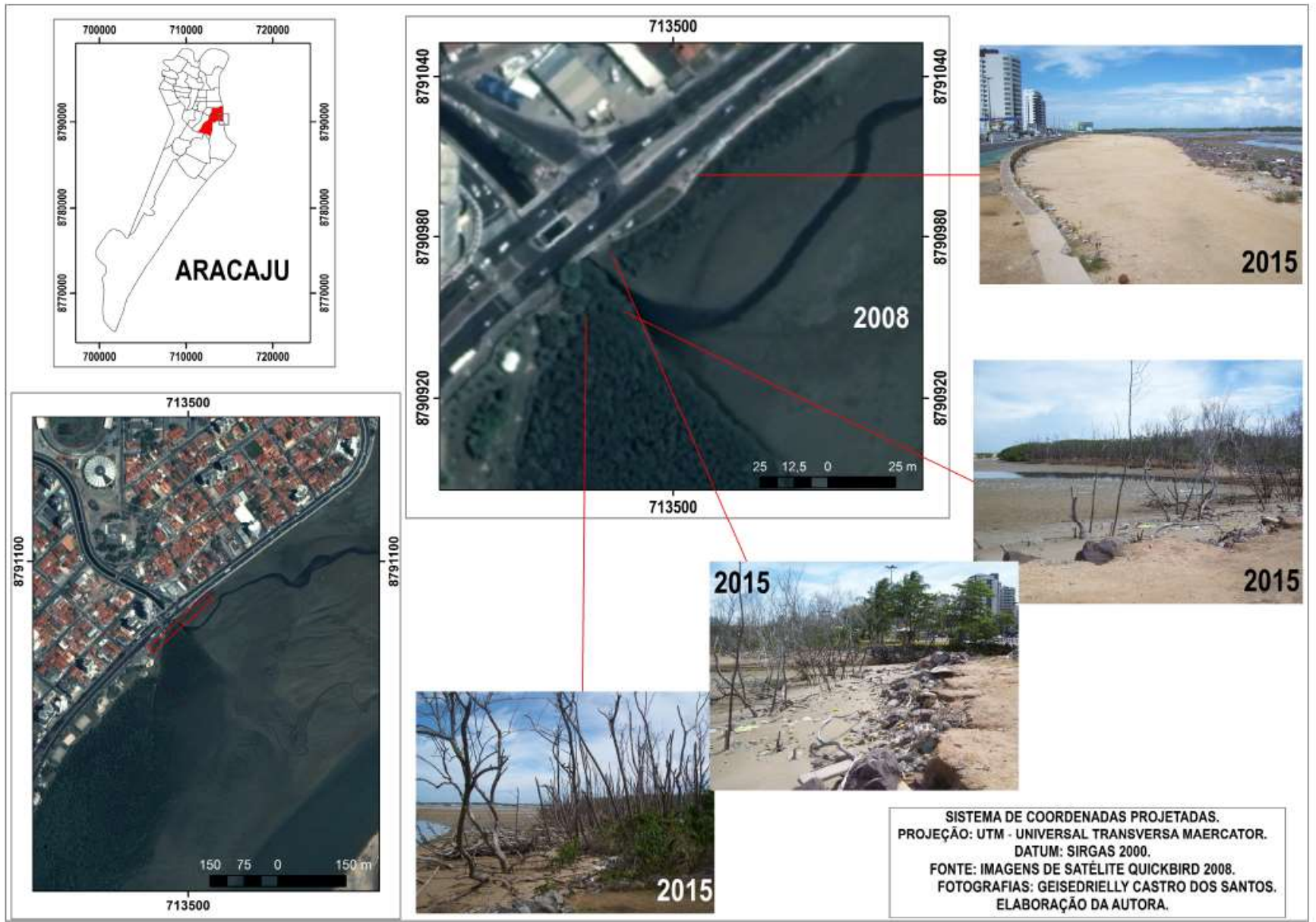

Figura 7 - Imagens atuais da área de estudo: Morte da vegetação pela sedimentação oriunda da erosão no Pontal arenoso

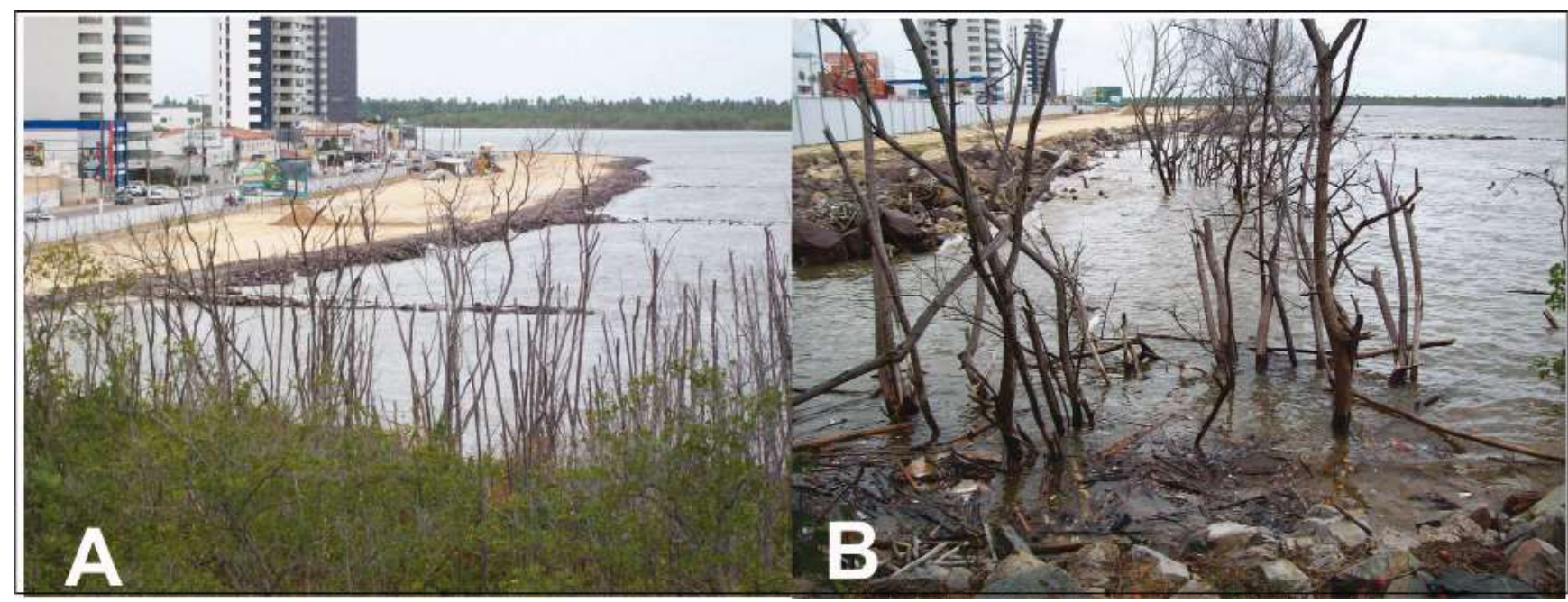

Figura 8 - Fotografias da área de estudo com obra de contenção durante a maré alta, com destaque para a vegetação morta.

O modelo indica que em canais estáveis a direção do acúmulo de sedimentos ocorre a updrift do delta de maré vazante com deflexão a downdrift. Esse processo pode ser facilmente verificável a partir da análise das figuras 2 e 9 . A figura 2 representa o processo de formação da Coroa do Meio na desembocadura do rio Sergipe, conforme descrito em FitzGerald et al. (2000) e em FitzGerald (1982), a partir do rompimento do delta de maré de vazante. Na figura 9 o modelo proposto pelos autores supracitados está acompanhado da 
dinâmica da desembocadura, com indicação do sentido do transporte longitudinal de sedimentos (NE-SW) e da direção do talvegue do rio Sergipe em direção ao Sul (OLIVEIRA, 2003). O processo de migração do talvegue do rio Sergipe para o sul foi verificado por
IPH, 1965; INPH, 1987 e INPH, 1990, a partir de estudos técnicos realizados na desembocadura do rio Sergipe, onde ficou evidenciado que essa era a causa dos processos erosivos instalados na margem direita da desembocadura (Coroa do Meio).

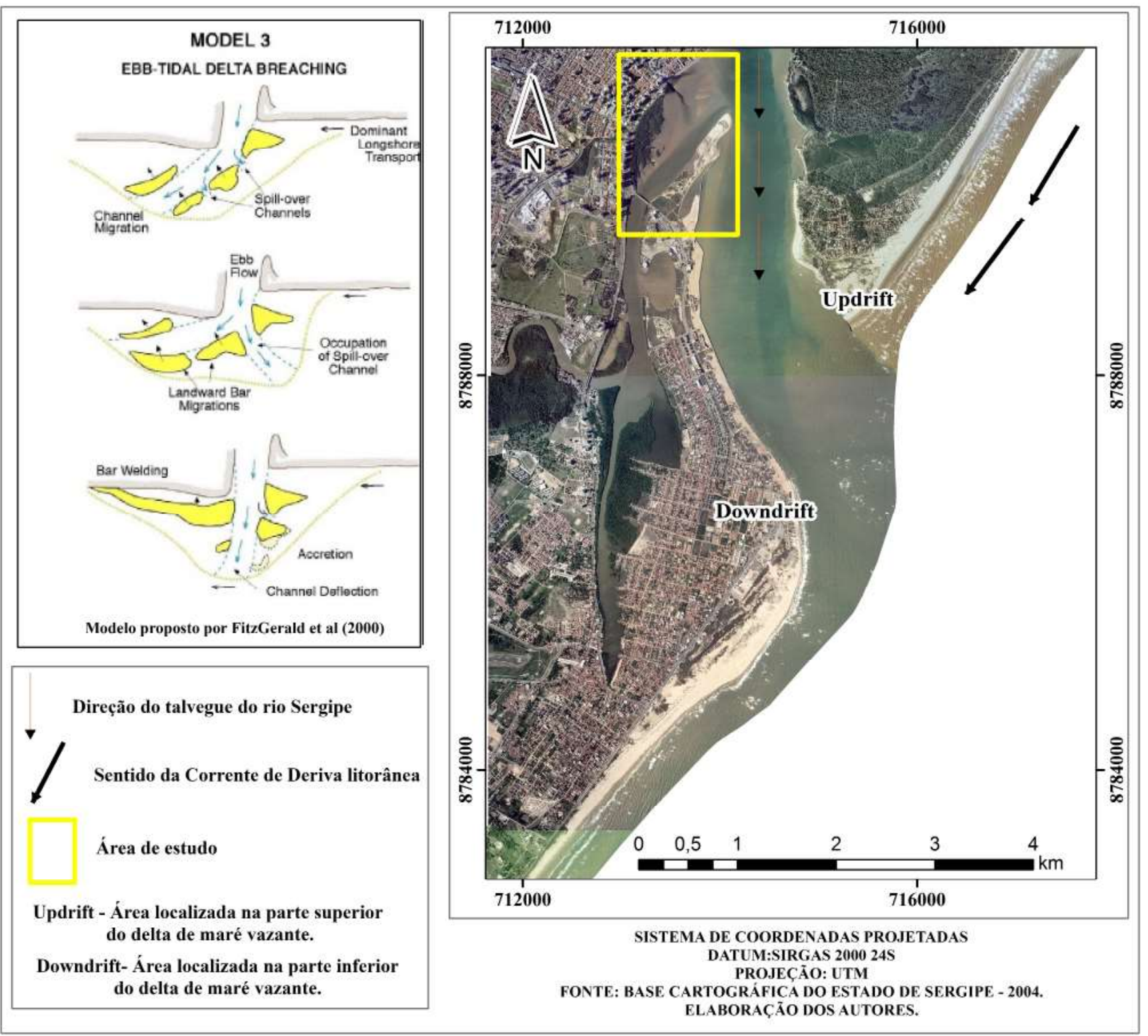

Figura 9-Modelo de rompimento do delta de maré vazante e dinâmica de transporte de sedimentos na área de estudo.

A morfodinâmica da área de estudo tem sua dinâmica associada à presença do promontório arenoso situado no bairro Coroa do Meio. A partir dos dados expostos ao longo do presente artigo foi verificado que o mesmo sofreu erosão total em toda a sua extremidade localizada nas proximidades da obra de contenção à erosão costeira. Santos (2012) analisou a dinâmica da linha de costa adjacente à localização do pontal arenoso da área de estudo. De acordo com a autora no período entre 1955 e 2008 ocorreu erosão da linha de costa na margem direita do rio Sergipe, bairro Coroa do Meio. Os processos erosivos foram intensificados devido ao aterramento de toda a área de manguezal existente no bairro Coroa do Meio que funcionava como molhe hidráulico. A autora a partir de suas análises associou os processos erosivos à dinâmica oceanográfica e a migração para o 
sul do talvegue do rio Sergipe (WANDERLEY, 2006; SANTOS, 2012). As análises feitas no presente artigo apontam que a erosão do pontal arenoso existente na Coroa do Meio também ocorreu devido à dinâmica fluviomarinha, representada pela migração do talvegue do canal do rio Sergipe para o sul e pela dinâmica do delta de maré vazante. $O$ aterramento da Coroa do Meio funciona como um obstáculo à passagem do fluxo fluvial e a dinâmica oceanográfica, como resultado tem-se a erosão costeira.

Wanderley (2013) atribuiu a formação de bancos arenosos sobre a planície de maré entre os bairros 13 de Julho e Jardins à confluência das desembocaduras dos rios Poxim e Sergipe. Contudo, se forem analisados os processos identificados nos mapeamentos dos anos de 2011 e 2014 conclui-se que os sedimentos depositados sobre a planície de maré possuem sua origem atribuída à erosão do pontal arenoso da Coroa do Meio, ocasionado pela dinâmica fluviomarinha e não somente pela sedimentação de origem fluvial.

A erosão no pontal arenoso da Coroa do Meio foi determinante para a alteração da dinâmica na planície de maré existente entre os bairros 13 de Julho e Jardins, tendo em vista que o mesmo oferecia proteção da ação mecânica das ondas. Sem a presença desse obstáculo os agentes fluviomarinhos intensificaram sua atuação sobre a área promovendo a sedimentação de grande parte da área colonizada pelo mangue, ocasionando a morte de parte da vegetação até o momento. Lugo \& Snedaker (1974) afirmam que a presença de aterros e excesso de sedimentação pode promover alterações estruturais nos bosques de mangue, tal qual ocorre na área de estudo.

A própria área de estudo exemplifica que em condições de estabilidade é possível que ocorra a expansão dos manguezais. Na retaguarda do pontal arenoso, alheio aos acontecimentos promovidos pela erosão de sua extremidade, a planície de maré se desenvolveu e foi colonizada por mangue, com valor de área passando de $0,032 \mathrm{~km}^{2}$, em 2004 , para $0,097 \mathrm{~km}^{2}$, em 2014. O processo evolutivo verificado no pontal arenoso enquadra-se no processo inicial proposto por Citrón (1987), nas etapas de: colonização pelo mangue e desenvolvimento do manguezal.

\section{Considerações Finais}

A partir do exposto concluiu-se que a estrutura do sistema ambiental representado pela desembocadura do rio Sergipe é composta pela planície de maré, pelo pontal arenoso, águas fluviais, oceânicas e ações antrópicas. A dinâmica em questão possui como principais agentes modeladores naturais: a migração do talvegue do rio Sergipe para o sul e os agentes oceanográficos (correntes costeiras, regime de marés e incidência das ondas). Dentro da visão Geoeccológica, esses seriam os responsáveis pela difusão do fluxo de matéria e energia na área de estudo. Nesse contexto se encaixa ainda as ações antrópicas como fator fundamental para o surgimento das áreas de manguezais, já que o pontal arenoso somente foi estabilizado graças ao aterramento da Coroa do Meio.

A área de planície de maré entre os bairros 13 de Julho e Jardins depende da existência do pontal arenoso da Coroa do Meio para manter-se resguardada da ação direta das ondas e da contínua migração do talvegue do rio Sergipe. Contudo, a análise multitemporal mostrada neste trabalho apontou que toda a extremidade do pontal arenoso foi erodida no período entre 2004 e 2014. Essa erosão foi determinante para a redução na área da planície de maré desprovida e colonizada por mangue, devido principalmente à sedimentação provocada pela migração dos sedimentos erodidos do pontal em direção ao manguezal.

Além da exposição da planície de maré à ação direta dos agentes fluviomarinhos, a erosão no pontal arenoso promoveu também o avanço das ondas sobre parte da infraestrutura urbana do município de Aracaju, o que levou a prefeitura municipal a construir uma obra de contenção onde antes existia parte do manguezal.

$\mathrm{Na}$ contrapartida do processo evolutivo da planície de maré entre os bairros 13 de Julho e Jardins, no período entre 2004 e 2014, a planície de maré existente na retaguarda do pontal arenoso se expandiu, graças ao isolamento da ação direta da dinâmica fluviomarinha.

O histórico da área de estudo revela um prognóstico difícil para a recuperação da planície de maré entre os bairros 13 de Julho e Jardins, tendo em vista que o foco principal deve ser a recuperação da área erodida no pontal, que somente acontecerá mediante intervenções antrópicas, com novo aterramento. Fato que também depende de estudos mais aprofundados sobre a dinâmica fluviomarinha no local e análise da viabilidade de tais intervenções.

A realização deste trabalho permitiu compreender a complexidade da dinâmica em ambientes de desem- 
bocaduras fluviais, em especial naquelas que possuem contato direto com o ambiente marinho, bem como o comportamento das planícies de marés em face das mudanças na dinâmica costeira. Esta pesquisa fornece subsídios para análises futuras que visem o planejamento ambiental em áreas costeiras urbanizadas, e para o monitoramento e conservação dos sistemas ambientais costeiros.

\section{Referências Bibliográficas}

ANGULO, R. J. O manguezal como unidade dos mapas geológicos. In: Simpósio de ecossistemas da costa sul e sudeste brasileira, 2, 1990, Águas de Lindóia. Resumos expandidos. São Paulo: ACIESP. v. 2, p.54-62, 1990.

BITTENCOURT, A. C. S. P.; MARTIN, L. ; DOMINGUEZ, J. M. L. ; FLEXOR, J. M. ; FERREIRA, Y. A.. Evolução Paleogeográfica Quaternária da Costa do Estado de Sergipe e da Costa Sul do Estado de Alagoas. Revista Brasileira de Geociências, v. 13, n. 2, p. 93-97, 1983.

CINTRÓN, G. Caracterización y manejo de áreas de manglar. In: Simpósio sobre Ecossistemas da Costa Sul e Sudeste brasileira, Cananéia, 1987. Síntese dos Conhecimentos. São Paulo: ACIESP, v. 3, p. 77-97. (Publicação da ACIESP, n. 54). 1987.

FITZGERALD, D. M. Sediment Bypassing at Mixed Energy Tidal Inlets. Coastal engeneering. n.18, 1982.

FITZGERALD, D. M. ; KRAUS, N. C.HANDS; E. B. Natural Mechanisms of Sediment Bypassing at Tidal Inlets. US Army Corps of Engineers. ERDC/CHL CHETN-IV-30 December 2000. 1-10.

INPH - INSTITUTO NACIONAL DE PESQUISAS HIDROVIÁRIAS. Parecer técnico sobre o projeto executivo do molhe a ser construído no ppontal norte e projeto básico da proteção do litoral da Coroa do Meio/Aracaju-SE. Rio de Janeiro, set/1990.

INPH - INSTITUTO NACIONAL DE PESQUISAS HIDROVIÁRIAS. Estudo em Modelo Reduzido de Fundo Móvel da Barra do Rio Sergipe/Aracaju-SE. Relatório Final. Rio de Janeiro, 1987.

IPH - INSTITUTO DE PESQUISAS HIDRÁULICAS. Projeto de Estudos na Natureza e em Modelo reduzido para Manutenção de Canal de Acesso através da Barra de Aracaju. Conselho de Desenvolvimento de Sergipe. Universidade do Rio Grande do Sul, Porto Alegre, 1965.
LUGO, A. E. \& SNEDAKER, S. C. The Ecology of Mangroves. Annual Review of Ecology and Systematics, v. 5 . p. 39-64, 1974.

MOnteiro, M. da G. A restinga da Atalaia: Uma contribuição ao estudo do litoral sergipano. 1963. 50 f. Tese (Concurso a cátedra de Geografia) - Colégio Estadual de Sergipe, Aracaju, SE, 1963.

NETO, J. A. B.; PONZI, V. R. A.; SICHEL, S. E. Introdução à Geologia Marinha. Editora Interciência, 2004.

OLIVEIRA, M. B. de. Caracterização integrada da linha de costa do estado de Sergipe - Brasil. 2003. 102f. Dissertação (Mestrado em Geologia) - Universidade Federal da Bahia, Salvador, BA, 2003.

SEMARH - Secretaria do Meio Ambiente e dos Recursos Hídricos de Sergipe. Plano estadual de recursos hídricos de Sergipe - PERH/SE. Aracaju: SEMARH, 2011.

PIANCA, C; MAZZINI, P. L. F.; SIEGLE, E. Brazilian offshore wave climate based on nww3 reanalysis. Brazilian Journal of Oceanography, v. $58 \mathrm{n}^{\mathrm{o}} 1$, p.53-70, 2010.

SANTANA, C. SEMARH conclui análise de fenômeno na 13 de Julho. Disponível em: http://www.infonet.com.br/cidade/ler. asp?id=137163. Acesso em 05 de maio de 2015.

SANTOS, G. C. Derivações antropogênicas e Evolução do manguezal nos bairros 13 de julho e Jardins em Aracaju-SE. Revista Brasileira de Geografia Física. v. 7 n.02. p. 278-290, 2014.

SANTOS, G. C. Dinâmica da paisagem costeira da Coroa do Meio e Atalaia - Aracaju/SE. 2012. 152f. Dissertação (Mestrado em Geografia) - Universidade Federal de Sergipe, São Cristóvão, SE, 2012.

SRH - Superintendência de Recursos Hídricos de Sergipe. Atlas digital sobre recursos hídricos, cd-rom, 2011.

SUGUIO, K. \& MARTIN, L. Quaternary marine formations of the State of São Paulo and Southern Rio de Janeiro. Special Publicacion nP 1. In: Suguio et al. (eds.), “1978 International Symposium on Coastal Evolution in the Quaternary”. 1978. $55 \mathrm{p}$.

TESSLER, M. G.; CAZZOLI \& GOYA, S. Processos costeiros condicionantes do litoral brasileiro. Revista do Departamento de Geografia - USP. p.11-23, 2005.

TROLL, C. Landscape Ecology (Geoecology) and Biogeocenology - A terminological Study. Geoforum, $n^{\circ} 8$, p. 43-46, 1970. 
Morfodinâmica do Pontal Arenoso e Interferências na Evolução da Planície de Maré na Desembocadura do Rio

WANDERLEY, L. L. Paisagem da janela: esse nosso inconstante rio Sergipe e a evolução de sua Foz. In: ALVES, J.P.H. (Org.).

Rio Sergipe: importância, vulnerabilidade e preservação/ Organização de José do Patrocínio Hora Alves. Aracaju-SE: Ós Editora. p. 167 - 194, 2006.

WANDERLEY, L.L. A dinâmica geomorfológica e urbano- ambiental do sistema flúvio-marinho rio Sergipe-rio Poxim, em Aracaju, Sergipe, nordeste do Brasil. Revista Geonordeste, Ano XXIV, n.2, p. 56-80, 2013.

ZENKOVICH, V. P. Processes of coastal development. London, 1967. 